\title{
Effect of Teacher's Guided Students Peer - Assessment on Teaching and Learning in a Large Class
}

\author{
Adeyemo Emily Oluseyi \\ Dept of Educational Foundations and Counselling \\ Faculty of Education, Obafemi Awolowo University, lle -lfe \\ Email: seyiadeyemo2007@yahoo.com
}

\section{Doi:10.5901/mjss.2014.v5n8p296}

\section{Abstract}

\begin{abstract}
The study investigated the performance of students in large class in Mathematics and English. It compared the performance of the students using guided peer and teacher's assessment strategies with a view to determine the impact of teacher's guided students' peer - assessment strategy on teaching and learning in a large class. The research design was experimental using control and study groups. The study population consisted of secondary school students in Osun State. One public secondary school was purposefully selected based on the size. Students in SSS2 were purposively chosen based on the fact that all the students offer Mathematics and English Language. The sample size for the study consisted of 119 students, 59 for the study group and 60 for the control groups. The instruments used for the study were Mathematics Achievement Test (MAT) and English Language Achievement Test (ELAT), designed by the subject teachers. The research was conducted giving treatment of peer - assessment for the study group while the control group was not giving treatment. The scores of the students both at post and pre-treatment were recorded and subjected to statistical analysis using F-test and t-test. The results revealed improvement in the performance of students when peer - assessment strategy was used (mean difference $=+10.1$ for study group and +0.5 for the control group) The scores of both teacher and students' peer - assessment were not significantly different ( $t=1.810, p=>0.05$ ) The mean difference in the performance of students in English Language for the study group was -3.9 and the control group was -15.7 . The reduction was much more at the control group but not significant with the study group $(t=0.973, p>0.05)$ but significant with the control group $(t=5.411, p<0.05)$. There was a significant difference in the performance of students in mathematics with peer - assessment, $(t=4.233, p<0.05)$ and English Language $(t=13.4, p<0.05)$ The study concluded that students performed better when peer assessment strategy was used and that it was possible for students to self- assessed themselves with accuracy even in a very large class where assessment could be too tedious for the teacher to carry out regularly and effectively.
\end{abstract}

Keywords: Guided peer-assessment, Large class, Mean difference, performance, teaching and learning.

\section{Introduction}

The extent to which the teaching activities fulfill its intended purposes, functions and goals matter so much in teaching and learning processes since this is a measure of teaching effectiveness. An institution that is committed to continual and meaningful improvement would be committed to continual and effective assessment.

The word assessment in Nigerian schools has been misleading and misinterpreted. The impression that both students and parents had was that all that matter in schools was to attain a certificate as if the means and measure of attaining it did not matter. This wrong impression led students to be involved in examination malpractices because they wanted to pass at all cost whereas assessment is more than passing examination or obtaining a better grade.

Assessment is the systematic collection, review and use of information about educational programme, undertaking for the purpose of improving students learning and development. Onuka and Oludipe (2006) viewed assessment as an effective tool of promoting students' achievement. Also, Onjewu (2006) defined assessment to include all the processes and products which described the nature and extent of learning, its degree of correspondence with the aims and objectives of teaching its relationship with the environment which are designed to facilitate schooling and learning. Assessment therefore is viewed to be an effective tool of promoting students achievement. The role of assessment in teaching and learning process cannot be over emphasized. Assessment when effectively carried out gives a comprehensive feedback on how well students understand the information and also helps the teachers to improve the design of the instruction.

In a large class, assessment might not be effective if it were to be the teacher alone doing the marking and grading. Assessment becomes more relevant when students take active part in it and it also serves as remedy for poor 
performance when regularly and comprehensively performed. Assessment that is teacher's dominated and the learners depend very much on teachers cannot make the students autonomous because the students need constant re-assurance from the teacher. Self assessment as an integral part of autonomous learning promote critical thinking in students. Self assessment, otherwise referred to as the Teacher -Initiated and guided students peer assessment (Unoka, 2007), is the test that the teacher gives to the students in class and gives them time to do and the teacher collects the papers and then work the solution on the chalkboard, in a guided way the teacher distributes this paper to students for marking, making sure that no student marks his or her paper while the teacher supervised the scoring and the recording.

Various problems have been found to associate with the introduction or use of self- assessment for evaluation purpose, among these were students' lack of accuracy between teacher's rating and students' self - rating. However, research studies (Blue1988), (Piece 1993), (Alvarez and Mufioz 2007), have demonstrated that students were able to assess themselves accurately and there can be correlation between teacher's assessment and students' selfassessment scores. Backkman and Palmer (1998) reported that self - rating is a reliable and a valid measure, in fact their views were that students have the ability to make precise and valid judgment about their own performance and that the judgment are reliable.

Anikwese (2005) observed that assessment takes place after learning but however the teacher - initiated and guided student - peer assessment has come up after one lesson before the commencement of another class. Self assessment helps students improve learning through the recognition of their own knowledge and abilities. When students are required to self assessed themselves, they exercised a variety of learning strategies and higher order thinking skills that not only provide the feedback to the students but also provide directions for their total learning (Mally 1994). Selfassessment is a way to bridge the gap between teacher and students' perception of the evaluation process as a way to foster students autonomy and improve students' learning,

It is difficult to set a definition of what a large class is as it varies from environment to environment. A class of 30 students may not be all large and wouldn't be considered as problematic, however some teachers have to face more than 40 to 60 students ,or even as large as up to 1500 students in a single cohort. Large classes are most common in the first year of study in the university and also in secondary schools where subjects like mathematics and English Language are being offered by all categories of students, be it science ,arts or social sciences. Large class size poses significant teaching challenges for teachers, not least especially in the assessment of learning. It limits the feedback provided to students. Teachers often complaint about teaching large classes, these unlucky teachers do not only suffer from pedagogical shortcomings of large classes but also from the stress these classes produce. However results of researchers showed that benefits in achievement generally occur when class size is reduced to less than 20 students.

In view of the fact that assessment forms an important part of any meaningful teaching method, much of what happened in the classroom is driven by it. Assessment is central to the overall quality of teaching and learning, since a well defined assessment sets clear expectations, establishes a reasonable workload on teachers, provides students the opportunity to self monitor their work because learners have delight in making decision unlike the teacher's made test and the standardized test which provide little information about students learning. In peer- assessment, learners are giving the opportunity and also take delight in making decision and valid judgment about their own performance, however, for many teachers the concept involved remain poorly defined and the area of self assessment is still largely neglected, the practice is the assessment that is teacher's dominated and the learners still depend solely on teacher's decision. This situation may arise due to the problems associated with self assessment among which is the correlation between teacher's rating and students' self - rating and also lack of accuracy. The aim of this study therefore was to determine the impact of teacher's guided student- peer assessment on teaching effectiveness in a large class. In view of this the following objectives were raised:

i. to investigate the performance of students of large class in Mathematics using guided peer assessment

ii. to investigate the performance of students of large class in English Language using guided peer assessment

iii. to compare performance of students of a large class using guided peer assessment with teacher's assessment

iv. to determine the effect of sex on students performance using peer and students' assessment in a large class

\section{Research Hypotheses}

i. There is no significant difference in the performance of students of large class in Mathematics using guided peer assessment.

ii. There is no significant difference in the performance of students of large class in English Language using guided peer assessment. 
iii. The performance of students with guided peer assessment in a large class are not significantly different from teacher's assessment

iv. Sex do not significantly affect the performance of students using peer and teacher's assessment.

\section{Methodology}

The research design used was experimental using study and control groups. The study population consisted of secondary school students in Osun state. Purposeful sampling technique was used to select one public secondary school in lle - Ife at the time of this study. Students in the SSS 2 class were purposively selected based on the fact that all the students offer Mathematics and English Language. The SS3 students could not be used for the study as at the time of the research because they were preparing for the SSC Examination while the SS1 students had not covered much of the syllabus. Two arms of the SS 2 classes were used, one for experimental and the other for the control group. The sample size consisted of 59 students for the experimental and also 60 students for the control group, this made the sample size to be 119. The instruments used for the study were the Mathematics Achievement Test (MAT) and English Language Achievement Test (ELMT), designed by the subject teachers who were experts in the subjects and had been the teaching the subjects for a period of not less than 10 years. These two instruments were pilot tested on students of similar class in another school who were not part of the participatory sample to enhance reliability of the items. The reliability was found to be 0.71 and 0.76 for both English Language and Mathematics respectively. The research was conducted giving treatment to the experimental group while the control group was not given any treatment. The treatment was that at the beginning of each lesson, a short test was conducted for the students on their previous topic, the teacher collected the scripts and worked out the solution to the problems with students on the chalkboard. .The teacher distributed the scripts to the students for marking, ensuring that no student mark his or her scripts. Their marks were recorded and the teacher proceeded to teach the class for the day. This exercise lasted for a period of eight weeks after which a post-test was conducted for both the experimental and the control groups A pre-test had earlier been conducted on both the experimental and control group to determine the level of academic performance of the students. Their scores were recorded and the data were analyzed using the t-test, F-test and graphical illustrations

\section{Results}

4.1 Hypothesis 1 There is no significant difference in the performance of students of large class in Mathematics using guided peer assessment

Table 1: Pairwise comparison of students' performance in Mathematics in a large class using peer assessment method

\begin{tabular}{lcc}
\hline & Study Group (N=59) & Control Group (N=60) \\
\hline & Mean \pm SD & Mean \pm SD \\
\hline Pre-test score in Mathematics & $22.9 \pm 30.5$ & $37.2 \pm 40.6$ \\
Post-test score in Mathematics & $33.0 \pm 34.9$ & $36.7 \pm 38.7$ \\
Mean Difference & 10.1 & 0.5 \\
$t$ & 1.810 & 0.076 \\
p-value & 0.076 & 0.940 \\
\hline
\end{tabular}

The initial average performance (Mean $\pm \mathrm{SD}$ ) of the students of a large class in Mathematics before introducing peer assessment was (22.9 \pm 30.5$)$. After peer assessment method was introduced, there was an increase by 10.1 in average students' performance. However, the increase in the students' performance after introducing peer assessment method was not significantly different from the initial performance $(t=-1.810 ; p=0.076)$. Hence, students' average performance in mathematics does not significantly improve using peer assessment method. 
4.2 Hypothesis 2 There is no significant difference in the performance of students of large class in English Language using guided peer assessment

Table 2: Pairwise comparison of students' performance in English in a large class using peer assessment method

\begin{tabular}{lcc}
\hline & Study Group (N=59) & Control Group (N=60) \\
\hline & Mean \pm SD & Mean \pm SD \\
\hline Pre-test score in English & $85.8 \pm 22.3$ & $79.7 \pm 23.5$ \\
Post-test score in English & $81.9 \pm 21.5$ & $64.0 \pm 20.8$ \\
Mean Difference & 3.9 & 15.7 \\
$t$ & 0.972 & 5.411 \\
p-value & 0.335 & $<0.001$ \\
\hline
\end{tabular}

The initial average performance (Mean $\mathbf{\pm S D}$ ) of the students in English Language before introducing peer assessment was (85.8 \pm 21.5$)$. After peer assessment method was introduced, there was a reduction in average students' performance by 3.9 Factor responsible for this reduction was unknown. However, the fall in the students' performance after introducing peer assessment method was not significantly different from the initial performance $(t=0.972 ; p=0.335)$. Hence, students' average performance in English does not significantly improve using peer assessment method.. However, the reduction in students' performance in English Language was not significant among the students in the study group contrary to the experience of students in the control group. It could be inferred therefore that peer assessment method used for students in the study group served as a palliative to the mass failure in English Language.

\subsection{Hypothesis 3 The performance of students with guided peer assessment in a large class are not significantly different} from teacher's assessment

Table 3: Comparison of Students' Performance using Peer and Teacher's assessment Methods

\begin{tabular}{lcccc}
\hline & Mean \pm SD & Mean Difference & T & P \\
\hline Mathematics & & & & \\
Peer Assessment & $32.5 \pm 28.4$ & 12.5 & 4.232 & $<0.001$ \\
Teacher's Assessment & $20.0 \pm 20.6$ & & & \\
\hline English & $77.8 \pm 18.4$ & 13.4 & 14.019 & $<0.001$ \\
Peer Assessment & $64.4 \pm 20.6$ & & & \\
Teacher's Assessment & & & \\
\hline
\end{tabular}

There was significant difference in students' performance in Mathematics with peers' assessment and with teacher's assessment methods ( $t=4.232 ; p<0.05)$; similarly, students' performance in English Language with peers' assessment and teacher's assessment methods ( $t=14.019 ; p<0.05)$.

Figure 1. Students' Performance with peers' and teacher's assessment methods by subject type

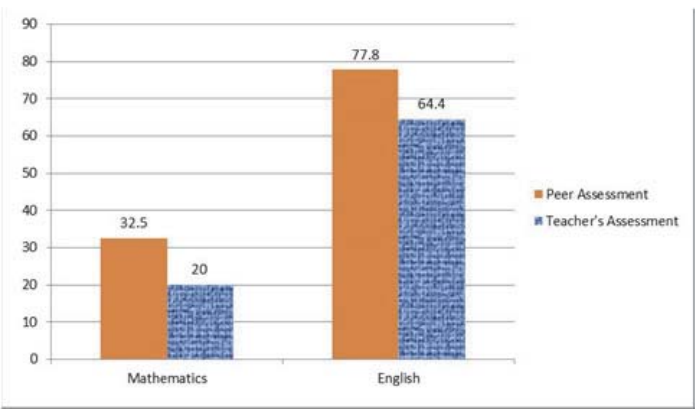

As shown in the figure 1 above, students' performance is higher in English Language with peers' (77.8\%) and teacher's 
assessment methods (64.4\%). Students performed much better using peers' assessment method than with teacher's assessment method in Mathematics than English Language

\subsection{Hypothesis 4 Sex do not significantly affect the performance of students using peer and teacher's assessment}

Table 4: Effect of sex on students' performance using peer and teacher's assessment

\begin{tabular}{lcccc}
\hline Peer Assessment & Mean \pm SD & Mean Difference & $\mathbf{t}$ & $\mathbf{P}$ \\
\hline Sex & & & & \\
Male & $52.4 \pm 32.8$ & 4.9 & 1.314 & 0.190 \\
Female & $47.5 \pm 32.9$ & & & \\
\hline Teacher's Assessment & & & & \\
Sex & & & & \\
Male & $41.6 \pm 29.6$ & 4.7 & & \\
Female & $36.9 \pm 29.1$ & & & \\
\hline
\end{tabular}

The table above showed the average performance of students using peer and teacher's assessment methods. Effect of gender on students' average performance was examined using the two assessment methods. The average performance of male students (52.4 \pm 32.8$)$ and female students $(47.5 \pm 32.9)$ was not significantly different $(t=1.314 ; p>0.05)$ using peer assessment method. Similarly, the average performance of male students (41.6 \pm 29.6$)$ and female students $(36.9 \pm 29.1)$ was not significantly different $(t=1.387 ; p>0.05)$.

Figure 2: Peers' and Teacher's Assessment methods among male and female students

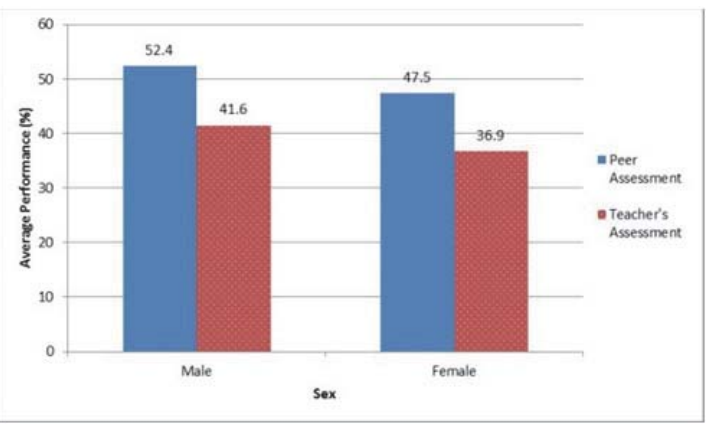

The figure 2 above showed that male students' performance was higher with peers' assessment method (52.4\%) than with teacher's assessment method (41.6\%). This was similar to the performance of female students using peers' (47.5\%) and teacher's assessment methods (36.9\%)

\section{Discussion}

The results of the study revealed that students' accuracy in self assessment was closely connected with what was obtained in the teacher's assessment procedures. This findings confirmed the work of Alvarez and Mufioz (2007) that students are capable of assessing themselves accurately. The non-significant difference in the results confirmed similarity in scoring between teacher's and students' assessment. The increase of 10.1 in the mean difference in the performance of students in mathematics after the treatment on the study group is an indication that the study group achieved a better result than the control group i.e. the study group performed better than the control group after the treatment. This provided answer to the first objective that the performance of students in large class in mathematics improved after the treatment using peer assessment but there was no significant difference in the performance $p<0.05$. The non- significant difference in the performance as compared with the control group confirmed the work of Alvarez and Mufioz (2007), indicating that students are able to assess themselves accurately and that there could be correlation between teacher's and students' self assessment. This also confirmed the work of Backham and Palmer (1989) that self rating is reliable and valid and that students have the ability to make precise and valid judgment about their own performance. Despite the 
fact that the performance of students in English Language reduced after the treatment among both the study and the control groups, the fall was much among the control group. (-3.9 for study group and -15.7 for the control group.) The reduction however is not significant among the study group $(p=0.972>0.05)$. Factors responsible for this low performance was not actually known but could not be far from any of the lack of guidance or support provided by the teacher, increasing linguistic complexity or the teacher's higher expectations and demands. The reason why the study group performed better could likely be because of the effect of the treatment. The treatment probably served as palliative for the mass failure in English Language. It could be inferred that peer assessment strategy used for the students in the study group served as a palliative to the mass failure in English Language. Arising from the significant difference in the performance of the students in the control group and the high failure rate that was more evident among them, it could therefore be inferred that peer-assessment is effective in improving students' learning and it also served as an effective tool of enhancing teaching effectiveness. This confirmed that peer-assessment significantly influences students' performance as indicated in Adeyemo,(2013) and that it could be used as remedy for poor performance just as Onuka and Oludipe (2004) discovered.

\section{Conclusion}

This study revealed that both peers' and teacher assessment were effective strategies in assessing students' performance and that it was possible for students to self- assessed themselves with accuracy even in a very large class where assessment could be too tedious for the teacher to carry out regularly and effectively.

\section{References}

Adeyemo. E. O. (2013) Students, peers and teacher's strategies as a measure of effective classroom assessment and the value of triangulation. A paper presented at the University of Western Cape at the International Conference on Research and Capacity Building, March 2013.

Alvarez, M. E. and Mufioz, A. (2007) Students' Objectivity and Perception of Self Assessment in an EFC Classroom The Journal of Asia Tefl Vol4 No 2 pp1-20.

Backham, I. \& Palmer, A.S (1989) The Construct Validity of Self- rating of Communicative Language ability. Language Testing 6 (1) ;1429.

Blue ,G.M. (1988) Self Assessment :The limit of Learner Independence. In Brookes A Grundy P. (eds) Individualization and autonomy in Language Learning. ELT bocuments 131 London Modern Publication in association with the British Council (Macmillian)

Gibbs, G. (1992) Improving the quality of Student Learning: Bristol Technical aid Educational Services.

Malley, J. M. \& Channot, A. (1990) Learning Strategies in Second Language acquisition Cambridge: Cambridge University Press

Mulligan, D. \& Kikpatrick. A. (2000). How much do they understand ? Lecturers, Students and comprehension, Higher Education Research and Development 19 (30, 311-335.

Onuka, A.O.U. and Oludipe, B.A.(2006) Systematic School Based for an improve Cognitive achievement. Academic Journal of Research and Development 1(10 1-12

Onjewu M.A. (2006) Teacher Motivation in the delivery of the "Use of English" course. The Kaduna Polytechnic Example. A paper presented at the National Conference organized by the Faculty of Education, University of Abuja $17^{\text {th }}-20^{\text {th }}$.

Piece, B.N. Swain, M, \& Hert, D (1993) Self Assessment, French immersion and Locus of Control Applied Linguistics 14(1) 25-42 